\title{
PENDATAAN ASET BIRO PENGELOLAAN BARANG MILIK NEGARA KEMENTERIAN PEKERJAAN UMUM DAN PERUMAHAN RAKYAT MENGGUNAKAN SISTEM INFORMASI GEOGRAFIS BERBASIS WEB
}

\author{
Arif Sudrajat ${ }^{1}$, Thomas Budiman ${ }^{2}$, Rachmawaty Haroen ${ }^{3}$, \\ Verdi Yasin 4 \\ Program Studi Sistem Informasi, Fakultas Ilmu Komputer ${ }^{1}$ \\ Program Studi Teknik Informatika, Fakultas Ilmu Komputer ${ }^{2}$ \\ Program Studi Sistem Informasi, Fakultas Ilmu Komputer ${ }^{3}$ \\ Program Studi Teknik Informatika, Fakultas Ilmu Komputer ${ }^{4}$ \\ Sekolah Tinggi Manajemen Informatika dan Komputer Jayakarta \\ Arifsudrajat20@gmail.com, thomas@stmik.jayakarta.ac.id, \\ rahmawatyharoen@gmail.com, verdiyasin29@gmail.com
}

Received: February 07, 2021. Revised: March 03, 2021. Accepted: April 22, 2021. Published: June 20, 2021. Issue Period: Vol.5 No.1 (2021), Pp.35-47

\begin{abstract}
Abstrak: Dalam melaksanakan tugas, Kementerian Pekerjaan Umum dan Perumahan Rakyat menyelenggarakan fungsi, salah satunya adalah pengelolaan barang milik/kekayaan negara yang menjadi tanggung jawab Kementerian Pekerjaan Umum dan Perumahan Rakyat. Untuk mendukung dan memenuhi tugas dan menjalankan fungsi kementerian pekerjaan umum dan perumahan rakyat telah melakukan pekerjaan pendataan aset secara manual untuk pekerjaan pengelolaan. Namun metode tersebut kurang efektif dan efisien dan juga belum cukup untuk memenuhi informasi yang dibutuhkan oleh pihak kementerian, sehingga kementerian akan mengalami kesulitan untuk menentukan perencanaan pengelolaan BMN untuk titik lokasi aset tanah maupun bangunan karena tidak tersedia sarana dan informasi seperti visualisasi tempat serta jarak antar titik lokasi yang tepat dan akurat.

Melalui perancangan dan pembuatan SIG pendataan aset berbasis web ini diharapkan dapat menampilkan gambaran peta aset tanah milik kementerian pekerjaan umum dan perumahan rakyat sehingga lebih efektif dan efisien bagi kinerja kementerian PUPR. Penyajian informasi dalam bentuk web akan memudahkan pihak kementerian untuk mengaksesnya.
\end{abstract}

Kata kunci: Sistem Informasi Geografis, Pendataan, Web

\begin{abstract}
To support and fulfill its duties and carry out its functions, the ministry of public works and public housing has carried out manual asset data collection for management work. However, this method is less effective and efficient and also not sufficient to meet the information required by the ministry, so the ministry will have difficulty determining BMN management plans for the location of land and building assets because there are no facilities and information such as visualization of places and distances between points. precise and accurate location.

Through designing and creating a web-based data collection GIS, it is hoped that it can display a map of land assets belonging to the ministry of public works and public housing so that it is more effective and efficient for the performance of the Ministry of PUPR Presentation of information in web form will make it easier for the ministry to access it.
\end{abstract}

DOI: $10.52362 /$ jisicom.v5i1.376

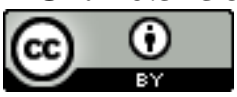

Ciptaan disebarluaskan di bawah Lisensi Creative Commons Atribusi 4.0 Internasional. 
Journal of Information System, Informatics and Computing

Website/URL: http://journal.stmikjayakarta.ac.id/index.php/jisicom

Email: jisicom@stmikjayakarta.ac.id , jisicom2017@gmail.com

Keywords: Geographic Information System, Data Collection, Web

\section{PENDAHULUAN}

1.1 Latar Belakang

Kementerian Pekerjaan Umum dan Perumahan Rakyat Republik Indonesia adalah kementerian dalam Pemerintah Indonesia yang membidangi urusan pekerjaan umum dan perumahan rakyat. Misi Kementerian Pekerjaan Umum dan Perumahan Rakyat yang merupakan rumusan upaya yang akan dilaksanakan selama periode Renstra 2020 - 2024 dalam rangka mencapai visi serta mendukung upaya pencapaian target pembangunan nasional, yaitu terwujudnya Infrastruktur Pekerjaan Umum dan Perumahan Rakyat yang Handal dalam mendukung Indonesia yang Berdaulat, Mandiri, dan Berkepribadian berlandaskan Gotong Royong. Dalam rangka pelaksanaan pembangunan infrastruktur, Kementerian PUPR banyak melakukan pembebasan lahan namun tidak diikuti dengan pengamanan administrasi yang seyogyanya dilaksanakan sejalan dengan pembangunan.

Untuk mendukung tugas serta menjalankan fungsi, kementerian pekerjaan umum dan perumahan rakyat telah melakukan pekerjaan pendataan aset tanah dan bangunan untuk pekerjaan pengelolaan aset secara manual. Namun metode tersebut kurang efektif dan efisien dalam masalah waktu dan juga belum cukup untuk memenuhi informasi yang dibutuhkan oleh pihak kementerian, sehingga pengelola akan mengalami kesulitan untuk menentukan perencanaan pengelolaan untuk titik lokasi aset tanah maupun bangunan karena tidak tersedia sarana seperti visualisasi tempat serta jarak antar titik lokasi yang akurat.

Oleh sebab itu, melalui perancangan dan pembuatan SIG pendataan aset Biro Pengelolaan BMN Kementerian PUPR ini diharapkan dapat menampilkan gambaran peta aset milik Biro Pengelolaan BMN kementerian PUPR sehingga lebih efektif dan efisien bagi kinerja kementerian. Penyajian informasi dalam bentuk web akan memudahkan pihak Biro Pengelolaan BMN kementerian PUPR untuk mengaksesnya.

\subsection{Identifikasi Masalah}

Berdasarkan latar belakang penelitian yang telah dijelaskan, maka timbul permasalahan sebagai berikut:

1. Metode Sistem pendataan aset milik Biro Pengelolaan BMN kementerian PUPR yang digunakan atau di kelola saat ini masih secara manual, sehingga kurang efektif dan efisien karena data atau informasi mengenai lokasi aset masih kurang dan tidak sesuai dengan kondisi saat ini.

2. Metode manual tersebut menyebabkan lambatnya pencarian data aset kementerian pekerjaan umum dan perumahan rakyat

\subsection{Pembatasan Masalah}

Adapun ruang lingkup dalam penelitian ini adalah sebagai berikut:

1. Bahwa pembahasan hanya pada perancangan Sistem Informasi Geografis (SIG) pendataan asset berbasis Web.

2. Menggunakan software Notepad ++ , Macromedia Dreamweaver dan XAMPP.

3. Data asset pendataan adalah asset yang berada di bawah penatausahaan Biro Pengelolaan BMN Kementerian PUPR yang berada di Provinsi DKI Jakarta.

\subsection{Perumusan Masalah}

Berdasarkan hasil Identifikasi Permasalahan diatas, maka rumusan masalah dalam penulisan skripsi ini adalah bagaimana membuat Sistem Informasi Geografis untuk Pendataan Aset Biro Pengelolaan BMN kementerian PUPR berbasis Web sehingga informasi mengenai data aset tanah dan bangunan yang dibutuhkan oleh Kementerian Pekerjaan Umum dan Perumahan Rakyat dapat diakses dengan cepat, tepat, lengkap, dan akurat.

\section{I.5 Kegunaan Penelitian}

Kegunaan dari penelitian ini adalah sebagai berikut:

1. Mempermudah persebaran asset Biro Pengelolaan BMN Kementerian PUPR di Provinsi DKI Jakarta melalui Sistem Informasi Geografis (SIG) berbasis Web untuk pendataan asset Biro Pengelolaan BMN Kementerian PUPR agar memudahkan dalam pencarian titik lokasi asset.

DOI: $10.52362 /$ jisicom.v5i1.376

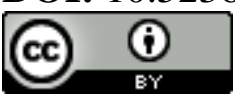

Ciptaan disebarluaskan di bawah Lisensi Creative Commons Atribusi 4.0 Internasional. 
Journal of Information System, Informatics and Computing

Website/URL: http://journal.stmikjayakarta.ac.id/index.php/jisicom

Email: jisicom@stmikjayakarta.ac.id , jisicom2017@gmail.com

2. Mempermudah pegawai Biro Pengelolaan BMN dalam mencari lokasi dan informasi asset di Provinsi DKI Jakarta.

\section{METODE DAN MATERI}

\subsection{Desain Penelitian}

Desain penelitian adalah tahapan atau gambaran yang akan dilakukan dalam melakukan penelitian yang memudahkan penulis dalam melakukan penelitian. Berikut adalah tahapan penelitian yang akan dilakukan penulis dalam proses penelitian skripsi yang berjudul "Pendataan Aset Biro Pengelolaan BMN Kementerian PUPR Menggunakan Sistem Informasi Geografis Berbasis Web” dapat dilihat secara jelas pada gambar dibawah ini untuk memecahkan permasalahan yang diangkat dalam penelitian ini.

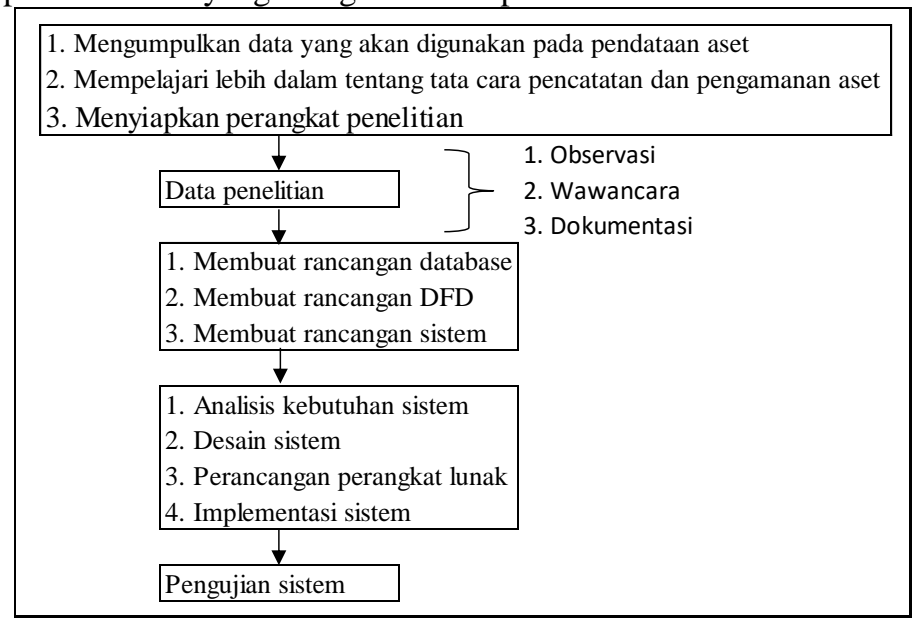

Gambar 1. Desain Penelitian

Dalam menyelesaikan penelitian ini, peneliti menggunakan pendekatan deskriptif, artinya data yang dikumpulkan bukan berupa angka, melainkan data yang berasal dari naskah wawancara, catatan lapangan, dokumen pribadi, catatan atau memo peneliti dan dokumen resmi lainnya yang mendukung. Peneliti juga menggunakan pendekatan kualitatif yang bertujuan agar peneliti dapat menggambarkan realitas empiris, teknik pengumpulan data dilakukan secara gabungan.

Tahap pra penelitian yang dilakukan dalam tahap ini adalah menyusun rancangan awal dalam penelitian, memastikan kondisi dan keadaan lapangan, serta mempersiapkan intrumen penelitian serta bahan yang diperlukan dalam proses penelitian.

Tahap penelitian yang dilakukan dalam penelitian ini adalah tahap pengumpulan data melalui pengambilan data spatial dan pengamatan lapangan. Penelitian dilakukan sesuai dengan rancangan penelitian yang telah ditetapkan pada saat pra penelitian, seperti memilih lokasi penelitian, melakukan pengambilan data spatial pada obyek kajian, melakukan pengamatan sesuai indicator yang telah ditentukan dalam hubungannya dengan kajian penelitian.

Tahap pasca penelitian, dalam tahap ini yang dilakukan adalah pengolahan data yang diperoleh pada saat penelitian. Data diolah melalui teknis analisis berdasarkan jenis datanya. Untuk data yang diperoleh dalam penelitian ini lebih bersifat kualitatif.

\subsubsection{Perancangan Database}

DOI: $10.52362 /$ jisicom.v5i1.376

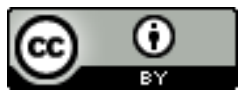

Ciptaan disebarluaskan di bawah Lisensi Creative Commons Atribusi 4.0 Internasional. 
e-ISSN : 2597-3673 (Online), p-ISSN : 2579-5201 (Printed)

Vol.5 No.1, Juni 2021

Journal of Information System, Informatics and Computing

Website/URL: http://journal.stmikjayakarta.ac.id/index.php/jisicom

Email: jisicom@stmikjayakarta.ac.id, jisicom2017@gmail.com

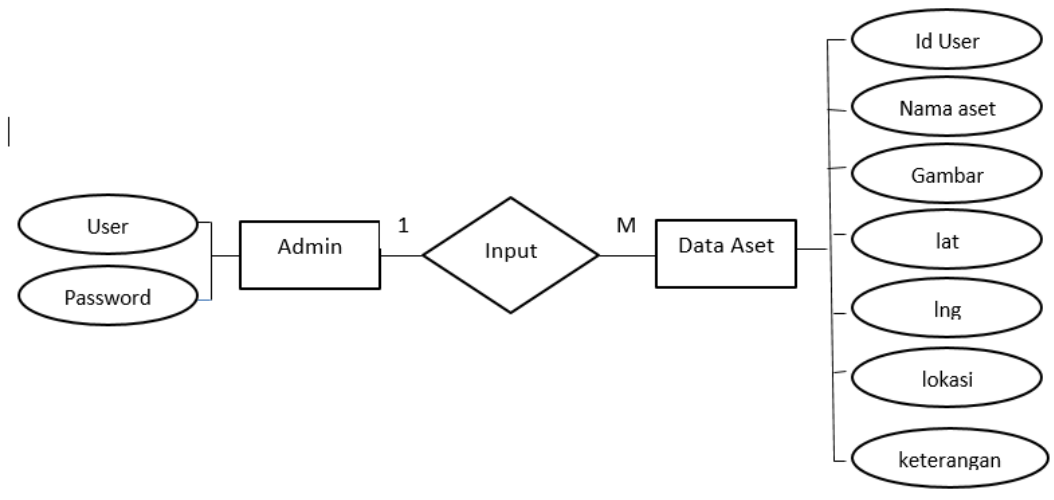

Gambar 2. Entity Relationship Diagram Pemetaan Aset

\begin{tabular}{|c|c|c|}
\hline Admin & \multirow[b]{2}{*}{ id } & gis \\
\hline username & & id_aset \\
\hline \multirow[t]{6}{*}{ password } & & nama_aset \\
\hline & & gambar \\
\hline & & lat \\
\hline & & Ing \\
\hline & & lokasi \\
\hline & & keterangan \\
\hline
\end{tabular}

Gambar 3. Logical Record Structure Pemetaan Aset

\subsubsection{Perancangan Sistem}

Perancangan pada sistem ini dibangun dengan menggunakan UML (Unified Modelong Language) yang meliputi Use Case Diagram, Flowchart, Activity Diagram dan Class Diagram

Use case diagram menjelaskan secara sederhana tentang fungsi sistem, pada sistem ini use case diagram hanya untuk admin saja.

DOI: $10.52362 /$ jisicom.v5i1.376

(c)

Ciptaan disebarluaskan di bawah Lisensi Creative Commons Atribusi 4.0 Internasional. 
e-ISSN : 2597-3673 (Online), p-ISSN : 2579-5201 (Printed)

Vol.5 No.1, Juni 2021

Journal of Information System, Informatics and Computing

Website/URL: http://journal.stmikjayakarta.ac.id/index.php/jisicom

Email: jisicom@stmikjayakarta.ac.id , jisicom2017@gmail.com

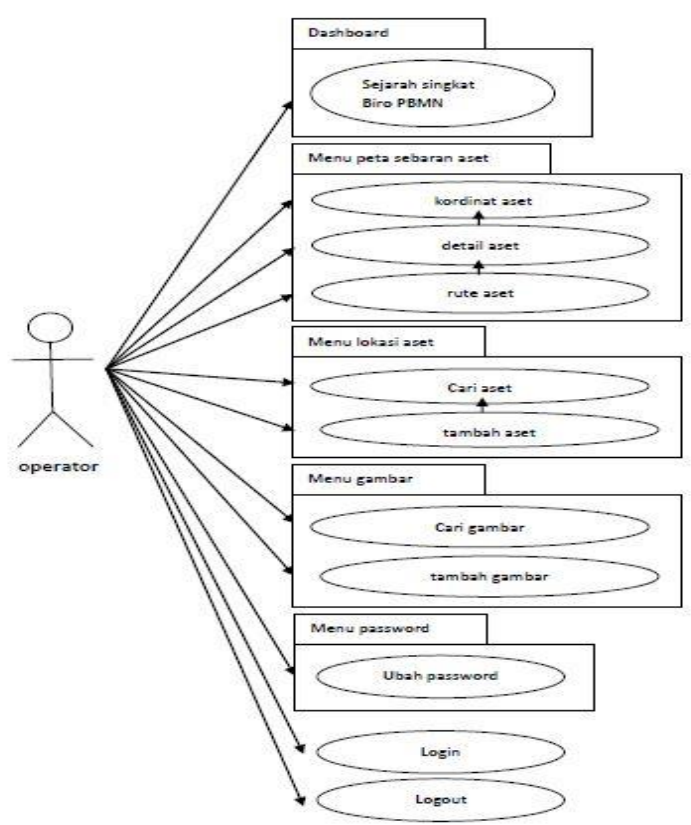

Gambar 4. Rancangan Use Case Diagram

Flowchart untuk pembangunan sistem ini dapat dilihat sebagai berikut:

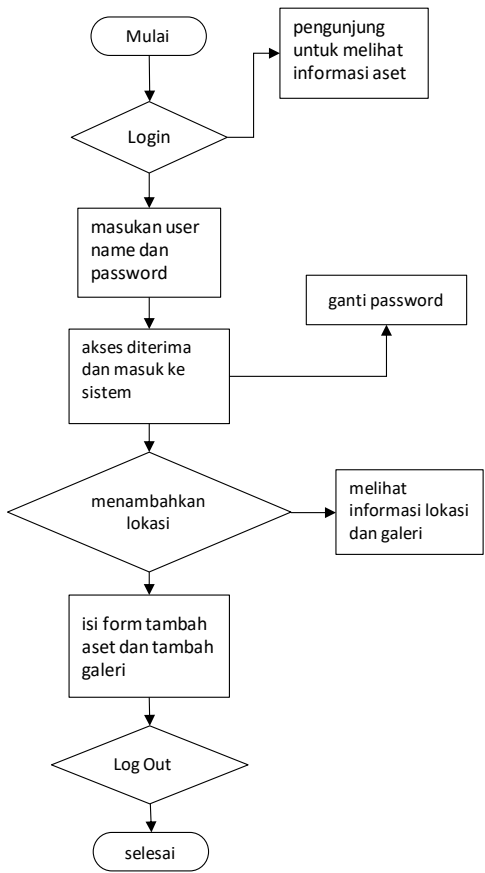

Gambar 5. Flowchart Sistem Informasi Geografis Pendataan Aset

DOI: $10.52362 /$ jisicom.v5i1.376

(c) (†)

Ciptaan disebarluaskan di bawah Lisensi Creative Commons Atribusi 4.0 Internasional. 
Journal of Information System, Informatics and Computing

Website/URL: http://journal.stmikjayakarta.ac.id/index.php/iisicom

Email: jisicom@stmikjayakarta.ac.id , jisicom2017@gmail.com

Activity Diagram adalah sebuah proses yang menampilkan proses aktifitas suatu sistem yang sedang dirancang, activity diagram untuk menambah lokasi baru pada sistem bisa dilihat pada gambar berikut

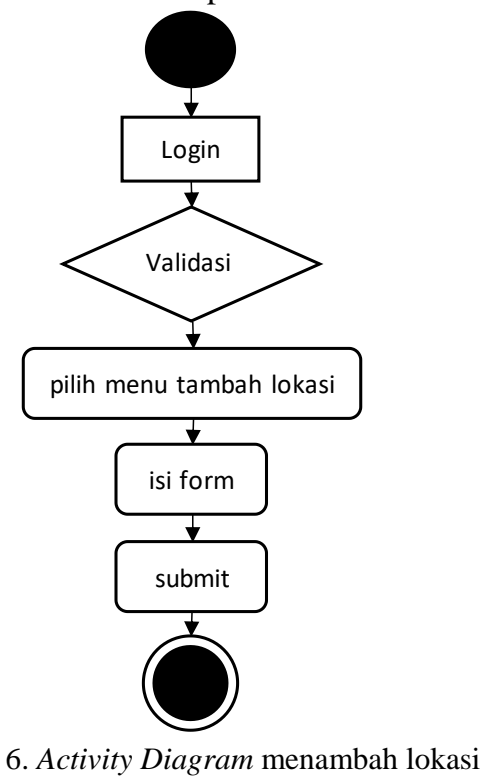

Class Diagram adalah diagram yang menggambarkan struktur dari segi pendefinisian kelas-kelas yang akan dibuat untuk membangun sistem, class diagram pada sistem ini dapat dilihat pada gambar berikut
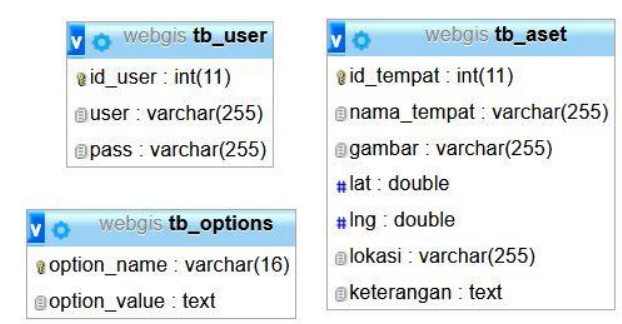

Gambar 7. Class Diagram

Prosedur perancangan aplikasi yang digunakan pada system informasi ini adalah menggunakan prosedur perancangan model waterfall, karena tahap demi tahap yang dilalui harus menunggu selesainya tahap sebelumnya dan berjalan berurutan. Model ini merupakan model pendekatan secara sistematis dan urut mulai dari level kebutuhan system lalu menuju ke tahap analisis, desain, coding, testing/verification dan maintenance.

DOI: $10.52362 /$ jisicom.v5i1.376

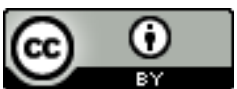

Ciptaan disebarluaskan di bawah Lisensi Creative Commons Atribusi 4.0 Internasional. 
Journal of Information System, Informatics and Computing

Website/URL: http://journal.stmikjayakarta.ac.id/index.php/jisicom

Email: jisicom@stmikjayakarta.ac.id , jisicom2017@gmail.com

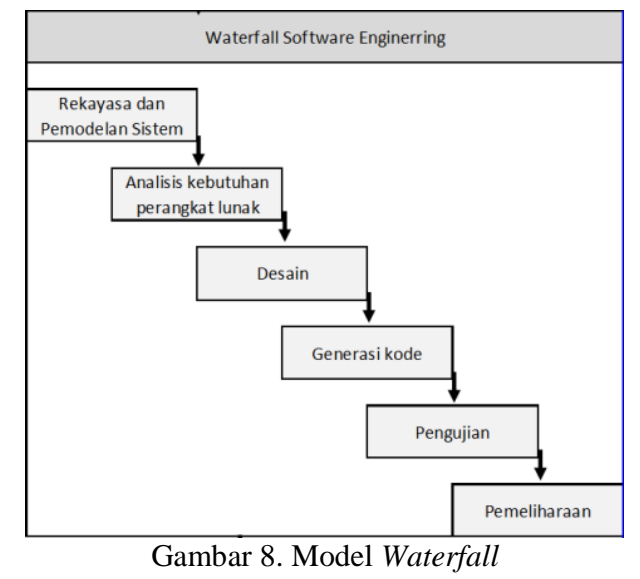

\subsection{Metode Pengumpulan Data}

Sebagai bahan untuk memperoleh data yang lengkap, akurat dan tepat untuk digunakan sebagai dasar untuk melengkapi pembuatan Sistem Informasi Geografis berbasis Web ini digunakan beberapa metode pengumpulan data, adapun metode tersebut adalah sebagai berikut:

1. Observasi Lapangan

Observasi yang dilakukan adalah penulis melakukan pengamatan dengan melakukan pencatatan atau pengkodean suatu aset langsung di lokasi aset-aset yang di identifikasi milik Kementerian PUPR. Beberapa informasi yang diperoleh dari hasil observasi adalah lokasi dan kebenaran informasi. Tujuan menggunakan metode ini untuk mencatat hal-hal, kondisi dan informasi lain terkait kondisi aset Biro Pengelolaan BMN Kementerian PUPR. Dengan observasi ini akan diperoleh data yang lengkap dan tepat, selain itu metode observasi mempunyai kelebihan yaitu peneliti mengetahui sendiri dengan jelas tentang kondisi lokasi saat ini. Proses penentuan lokasi aset Biro Pengelolaan BMN Kementerian PUPR dilakukan dengan cara mapping, yang digunakan untuk mendapatkan titik kordinat mengenai lokasi aset Biro Pengelolaan BMN Kementerian PUPR yang berada di Provinsi DKI Jakarta.

2. Wawancara

Pengumpulan data dengan cara wawancara dilakukan dengan cara mencari informasi dan bertanya langsung kepada petugas Pengelolaan BMN dan salah seorang informan yaitu pensiunan pegawai Kementerian PUPR yang merupakan pelaku sejarah, dimana dahulu mereka mengetahui dengan pasti lokasi-lokasi mana saja yang pernah dilakukan pembebasan oleh kementerian PUPR ketika proses pembangunan infrastruktur. Metode ini dilakukan dengan lisan dan dijawab dengan lisan untuk mendapatkan keterangan-keterangan pelengkap guna kelancaran kegiatan penelitian ini. Tujuan peneliti menggunakan metode ini adalah agar memperoleh data secara jelas dan pasti tentang informasi lokasi aset-aset Kementerian PUPR di Provinsi DKI Jakarta.

3. Dokumentasi

Dalam metode studi dokumentasi ini, peneliti mendapatkan beberapa dokumen dari berbagai sumber, termasuk sumber internal Kementerian PUPR serta dari sumber lainnya, antara lain dokumen resmi berupa arsip, notulensi dan beberapa peta pembebasan lahan. Selanjutnya sebagai dokumentasi pribadi, peneliti memiliki foto-foto kondisi aset saat ini. Secara umum studi dokumentasi dipilih sebagai salah satu metode pengumpulan data yang digunakan dalam penelitian ini yang bertujuan untuk melengkapi informasi deskriptif.

\subsection{Aset Barang Milik Negara}

Pengertian aset adalah suatu barang yang memilili nilai ekonomi, nilai komersial, ataupun nilai tukar suatu perusahaan atau indivisu, aset dapat pula didefinisikan sebagai seluruh kekayaan milik pemerintah. Definisi aset menurut Standar Akuntansi Pemerintah lebih luas lagi dan komprehensif, yaitu sumber daya ekonomi yang dikuasai dan/atau dimiliki oleh pemerintah sebagai akibat dari peristiwa masa lalu dan dari mana

DOI: $10.52362 /$ jisicom.v5i1.376

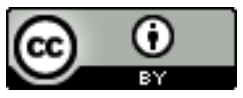

Ciptaan disebarluaskan di bawah Lisensi Creative Commons Atribusi 4.0 Internasional. 
Journal of Information System, Informatics and Computing

Website/URL: http://journal.stmikjayakarta.ac.id/index.php/jisicom

Email: jisicom@stmikjayakarta.ac.id , jisicom2017@gmail.com

manfaat ekonomi dan/atau sosial dimasa depan yang diharapkan dapat diperoleh, baik oleh pemerintah maupun masyarakat, serta dapat diukur dalam satuan uang, termasuk sumber daya non-keuangan yang diperlukan untuk penyediaan jasa bagi masyarakat umum dan sumber daya yang dipelihara karena alasan sejarah dan budaya.

\subsection{Sistem Informasi Geografis}

Secara umum, sistem merupakan perpaduan beberapa unsur yang tergabung satu dengan yang lain untuk memudahkan perpindahan informasi, energy maupun materi agar mencapai tujuan tertentu. Sistem berasal dari bahasa latin (systèma) dan bahasa yunani (sustèma) adalah suatu kesatuan yang terdiri dari komponen atau elemen yang dihubungkan bersama untuk memudahkan aliran informasi, materi atau energy untuk mencapai suatu tujuan [1].

Informasi adalah data yang telah diolah menjadi suatu bentuk yang penting bagi si penerima dan mempunyai nilai yang nyata yang dapat dirasakan dalam keputusan-keputusan yang sekarang atau keputusankeputusan yang akan datang [2].

Istilah sistem informasi geografi merupakan gabungan dari tiga unsur pokok yaitu sistem, informasi, dan geografi. Dengan demikian, pengertian terhadap ketiga unsur-unsur pokok ini akan sangat membantu dalam memahami SIG. Dengan melihat unsur-unsur pokoknya, maka jelas SIG merupakan salah satu sistem informasi. SIG merupakan suatu sistem yang menekankan pada unsur informasi geografi. Istilah "geografis" merupakan bagian dari spasial (keruangan). Kedua istilah ini sering digunakan secara bergantian atau tertukar hingga timbul istilah yang ketiga, geospasial. Ketiga istilah ini mengandung pengertian yang sama di dalam konteks SIG. Penggunaan kata "geografis" mengandung pengertian suatu persoalan mengenai bumi: permukaan dua atau tiga dimensi. Istilah "informasi geografis" mengandung pengertian informasi mengenai tempat-tempat yang terletak di permukaan bumi, pengetahuan mengenai posisi dimana suatu objek terletak di permukaan bumi, dan informasi mengenai keterangan-keterangan (atribut) yang terdapat di permukaan bumi yang posisinya diberikan atau diketahui [3].

\subsection{Web/Website}

Website sering disebut Web, dapat diartikan kumpulan-kumpulan halaman yang menampilkan berbagai macam informasi teks, data, gambar diam ataupun bergerak, data animasi, suara, video maupun gabungan dari semua itu, baik itu yang bersifat statis maupun yang dinamis, yang dimana membentuk suatu rangkaian bangunan yang saling berkaitan dimana masing-masing dihubungkan dengan jaringan halaman atau hyperlink. Definisi website adalah kumpulan dari berbagai macam halama situs, yang terangkum didalam sebuah domain atau juga sub domain, yang tempatnya berada di dalam WWW (World Wide Web) yang tentunya di dalam internet [4].

\subsection{Macromedia Dreamweaver}

Dreamweaver adalah Software yang digunakan oleh web toolbar, dimana bias digunakan untuk memodifikasi toolbar yang sudah ada atau menambahkan fungsi baru. Selain user interface baru, Dreamweaver memiliki kemampuan untuk menyunting koda dengan lebih baik. Dapat melakukan print kode pada jendela Code View, selain itu juga memiliki fasilitas Code Hints yang membantu dalam urusan tag. Serta Tag Inspector yang sangat berguna dalam menangani tah HTML [5].

Dreamweaver adalah sebuah HTML editor professional untuk mendesain web secara visual dan mengelola situs atau halaman web. Saat ini terdapat software dari kelompok Adobe yang belakangan banyak digunakan untuk mendesain sebuah situs web. Versi terbaru dari Adobe Dreamweaver saat ini adalah CS6, pada Dreamweaver CS6 terdapat beberapa kemampuan bukan hanya sebagai software untuk mendesain web saja tetapi juga untuk menyunting kode serta pembuatan aplikasi web dengan menggunakan berbagai bahasa pemrograman web dengan menggunakan berbagai bahasa pemrograman web, antara lain HTML, PHP, CSS, JavaScript, dan lain lain [6].

\subsection{XAMPP}

XAMPP merupakan paket PHP berbasis open source. Informasinya dapat diperoleh di website resminya: http://www.apachefriends.com. XAMPP membantu memudahkan dalam mengembangkan aplikasi berbasis

DOI: $10.52362 /$ jisicom.v5i1.376

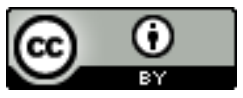

Ciptaan disebarluaskan di bawah Lisensi Creative Commons Atribusi 4.0 Internasional. 
Journal of Information System, Informatics and Computing

Website/URL: http://journal.stmikjayakarta.ac.id/index.php/jisicom

Email: jisicom@stmikjayakarta.ac.id, jisicom2017@gmail.com

PHP. XAMPP mengkombinasikan beberapa paket software berbeda kedalam satu paket. Adapun lisensi masingmasing paket software tersebut dapat ditemukan didirektori lxampp\licence. XAMPP menyediakan antar muka control panel tersendiri yang dapat digunakan untuk menjalankan semua service (paket software pendukung) yang telah terinstal. Pada sistem operasi windows, control panel dapat diakses melalui menu [Start]-[Program][Apachefriends]-[xampp]-[control xampp server panel]. Pada web server (lokal komputer, tidak di server internet sesungguhnya) pada XAMPP, akan menyediakan satu folder kerja yang bernama htdocs. Pada paket ini, folder kerja tersebut dapat ditemukan pada subfolder C:I..IXAMPP (sesuai lokasi dimana menyimpan hasil instalasinya) [7].

2.8 PHP

PHP pertama kali ditemukan pada tahun 1995 oleh seorang Software Developer bernama Rasmus Lerdrof. Ide awal PHP adalah ketika itu Radmus ingin mengetahui jumlah pengunjung yang membaca resume online-nya. Script yang dikembangkan baru dapat melakukan dua pekerjaan, yakni merekam informasi visitor, dan menampilkan jumlah pengunjung dari suatu website. Dan sampai sekarang kedua tugas tersebut masih tetap populer digunakan oleh dunia web saat ini.Kemudian, dari situ banyak orang di milis mendiskusikan script buatan Rasmus Lerdrof, hingga akhirnya Rasmus mulai membuat sebuah tool/script, bernama Personal Home Page (PHP) [8].

2.9 $M y S Q L$

MySQL adalah sebuah implementasi dari sistem manajemen basis data relasional (RDBMS) yang didistribusikan secara gratis. Setiap pengguna dapat secara bebas menggunakan $M y S Q L$, namun dengan batasan perangkat lunak tersebut tidak boleh dijadikan produk turunan yang bersifat komersial. $M y S Q L$ sebenarnya merupakan turunan salah satu konsep utama dalam basis data yang telah ada sebelumnya SQL (Structured Query Language). $S Q L$ adalah sebuah konsep pengoperasian basis data, terutama untuk pemilihan atau seleksi dan pemasukan data, yang memungkinkan pengoperasian data dikerjakan dengan mudah secara otomatis [9].

2.10 Notepad ++

Notepad++ adalah code editor (software penyuting kode) yang mendukung berbagai bahasa pemograman seperti HTML, CSS, PHP, JAVA, dan lain-lain yang dpat bekerja pada Sistem Operasi Windows. Kelebihan Notepad++ jika dibanding notepad bawaan windows adalah memiliki kelengkapan fitur untuk mempermudah pengguna saat mengedit kode termasuk saat mengedit HTML dan kode CCS [10].

\subsection{Google Maps API}

Penelitian tentang desain aplikasi ini berbasis WebGIS yang terintegrasi dengan Google Maps API. Google Maps adalah sebuah jasa peta globe virtual gratis dan online disediakan oleh Google dapat ditemukan di http://maps.google.com. Ia menawarkan peta yang dapat diseret dan gambar satelit untuk seluruh dunia dan baru-baru ini, Bulan, dan juga menawarkan perencana rute dan pencari letak bisnis di U.S., Kanada, Jepang, Hong Kong, Cina, UK, Irlandia (hanya pusat kota) dan beberapa bagian Eropa. Google Maps masih berada dalam tahap beta.Google Maps API merupakan aplikasi interface yang dapat diakses lewat javascript agar Google Map dapat ditampilkan pada halaman web yang sedang kita bangun. Untuk dapat mengakses Google Maps, Kita harus melakukan pendaftaran Api Key terlebih dahulu dengan data pendaftaran berupa nama domain web yang kita bangun [7].

\section{PEMBAHASA DAN HASIL}

\subsection{Implementasi Basis Data}

Implementasi basis data merupakan impelemntasi dari perancangan physical design basis data yang telah dirancang sebelumnya. Basis data pada sistem ini, yaitu basis data gis menghasilkan 4 tabel yaitu: tabel asset, tabel galeri, tabel option, dan tabel user. Implementasi basis data dan tabel pada sistem adalah sebagai berikut :

DOI: $10.52362 /$ jisicom.v5i1.376

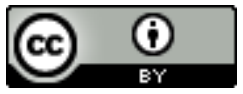

Ciptaan disebarluaskan di bawah Lisensi Creative Commons Atribusi 4.0 Internasional. 
e-ISSN : 2597-3673 (Online), p-ISSN : 2579-5201 (Printed)

Vol.5 No.1, Juni 2021

Journal of Information System, Informatics and Computing

Website/URL: http://journal.stmikjayakarta.ac.id/index.php/iisicom

Email: jisicom@stmikjayakarta.ac.id, jisicom2017@gmail.com

\begin{tabular}{|c|c|c|c|}
\hline \# Name & Type & Collation Attributes Null Default Extra & Action \\
\hline$\square^{1}$ id_aset & int(11) & No None AUTO_ & 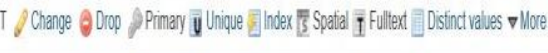 \\
\hline$]^{2}$ nama_aset & varchar(255) & Yes NULL & 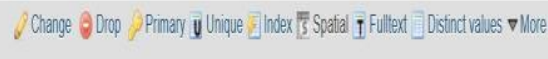 \\
\hline$]^{3}$ gambar & varchar(255) & Yes NULL & 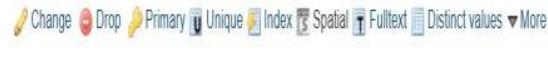 \\
\hline$]^{4}$ lat & double & Yes NULL & 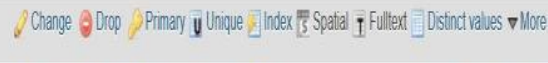 \\
\hline$\square^{5 \operatorname{lng}}$ & double & Yes NULL & 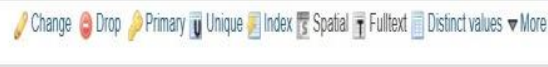 \\
\hline$\square^{6 \text { lokasi }}$ & varchar(255) & Yes NULL & 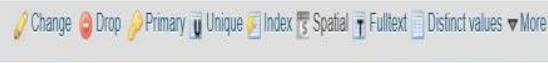 \\
\hline$]^{7 \text { keterangan }}$ & & Yes NULL & 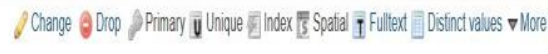 \\
\hline
\end{tabular}

Gambar 9. Implementasi Tabel Aset

\subsection{Implementasi Tampilan Home Page}

Halaman home page menyajikan sekilas pandang mengenai sejarah Biro pengelolaan BMN Kementerian Pekerjaan Umum dan Perumahan Rakyat. Pada halaman home page pengunjung dapat memilih menu peta sebaran asset untuk melihat data sebaran asset Biro Pengelolaan BMN Kementerian PUPR, dan untuk operator dapat memilih menu login untuk menambah dan mengurangi data yang akan disajikan oleh sistem.

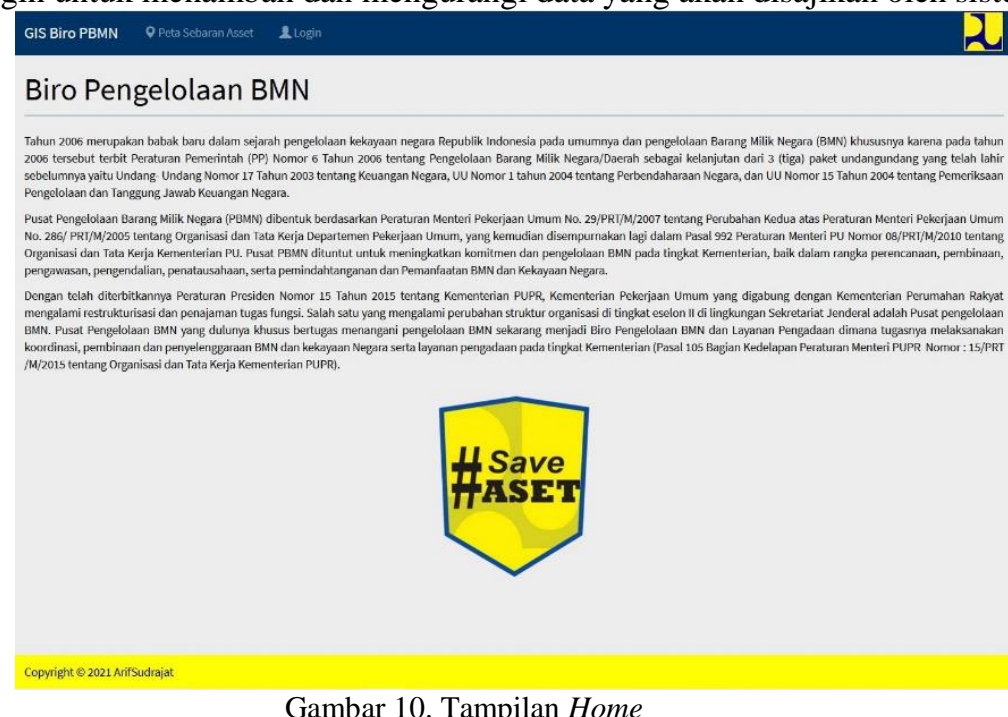

Gambar 10. Tampilan Home

\subsection{Implementasi Tampilan Lokasi Aset}

Pada halaman lokasi asset pengunjung dapat melihat informasi sebaran asset Biro Pengelolaan BMN Kementerian PUPR di Provinsi DKI Jakarta.

DOI: $10.52362 /$ jisicom.v5i1.376

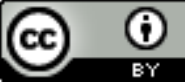

Ciptaan disebarluaskan di bawah Lisensi Creative Commons Atribusi 4.0 Internasional. 
e-ISSN : 2597-3673 (Online) , p-ISSN : 2579-5201 (Printed)

Vol.5 No.1, Juni 2021

Journal of Information System, Informatics and Computing

Website/URL: http://journal.stmikjayakarta.ac.id/index.php/jisicom

Email: jisicom@stmikjayakarta.ac.id, jisicom2017@gmail.com

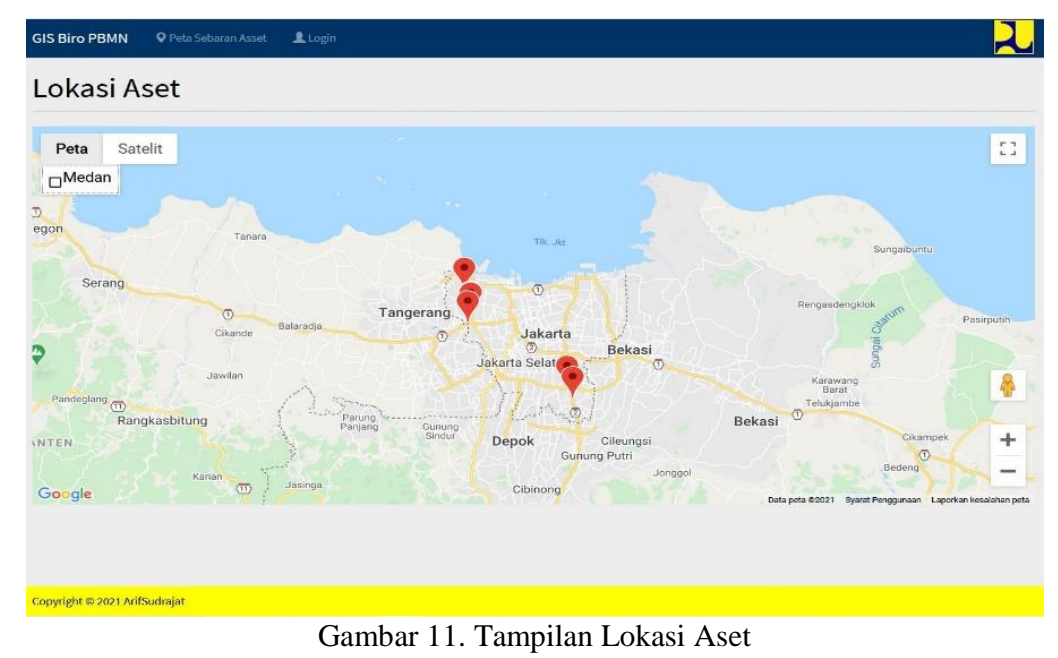

3.4 Implementasi Tampilan Rute Lokasi

Pada halaman ini kita dapat melihat rute terdekat menuju lokasi dari posisi kita melalui menu tampilkan rute.

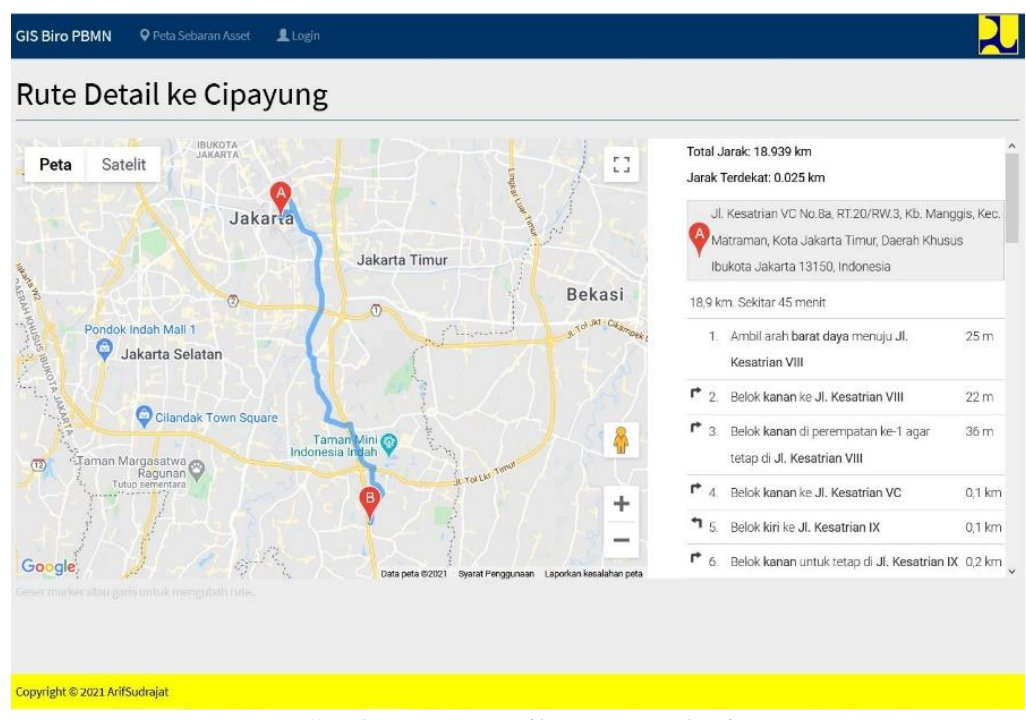

Gambar 12. Tampilan Rute Lokasi

3.4 Implementasi Tampilan Lokasi Aset

Pada halaman lokasi asset, operator bisa menambah data lokasi asset dengan klik menu tambah.

DOI: $10.52362 /$ jisicom.v5i1.376

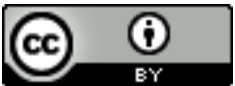

Ciptaan disebarluaskan di bawah Lisensi Creative Commons Atribusi 4.0 Internasional. 
Journal of Information System, Informatics and Computing

Website/URL: http://journal.stmikjayakarta.ac.id/index.php/jisicom

Email: jisicom@stmikjayakarta.ac.id , jisicom2017@gmail.com

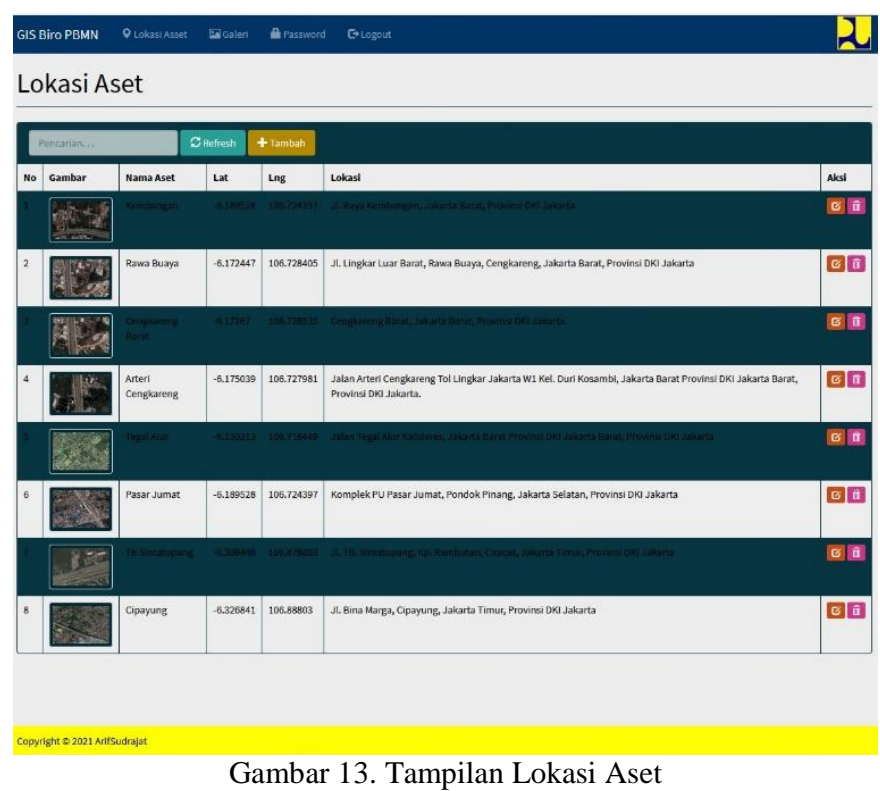

\subsection{Pembahasan}

Sistem Informasi Geografis berbasis Web Pendataan Aset Biro Pengelolaan BMN Kementerian PUPR memberikan informasi tentang lokasi sebaran aset pada Provinsi DKI Jakarta. Sistem ini dibangun menggunakan Macromedia Dreamweaver sebagai media untuk mendesain tampilan website, Notepad++ untuk mengolah script PHP dan XAMPP, untuk database yang digunakan dalam penyimpanan data adalah MySQL, ini merupakan database opensource yang cukup popular karena ketangguhannya dan kemampuannya dalam mengelola data, MySQL merupakan database yang penulis gunakan dalam mengelola data spasial.

Perancangan pada sistem ini dibangun dengan menggunakan UML (Unified Modelong Language) yang meliputi Use Case Diagram, Flowchart, Activity Diagram dan Class Diagram. Untuk perancangan modul dibangun dengan menggunakan API Google Maps dan script PHP, dengan API tersebut didapatkan peta yang sama dengan fitur milik Google Maps sehingga penulis hanya focus untuk mengolah peta tersebut yang digabungkan denga data-data atribut.

Prosedur perancangan aplikasi yang digunakan pada system informasi ini adalah menggunakan prosedur perancangan model waterfall, karena tahap demi tahap yang dilalui harus menunggu selesainya tahap sebelumnya dan berjalan berurutan. Model ini merupakan model pendekatan secara sistematis dan urut mulai dari level kebutuhan system lalu menuju ke tahap analisis, desain, coding, testing/verification dan maintenance. Pengembangan Sistem Informasi Geografis ini juga menggunakan Analisa Proses Sistem Berjalan (SWOT) penulis gunakan untuk mengetahui kekuatan (Strength) apa yang dimiliki oleh Biro Pengelolaan BMN Kementerian PUPR dari analisa system informasi geografis yang dilakukan. Kelemahan (Weakness) apa yang dimiliki juga perlu untuk diidentifikasi lebih awal guna melihat proses bisnis yang ada pada saat ini.

Dan terakhir adalah metode Pengujian, metode pengujian yang dipilih oleh penulis adalah metode Blackbox Testing System karena hal ini diperlukan untuk mengetahui sejauh mana dan apakah sistem sudah sesuai dengan apa yang diharapkan oleh penulis, metode ini menguji perangkat lunak dari segi spesifikasi fungsional tanpa menguji desain code program. Blackbok Testing System sebagai metodologi yang memfokuskan pada keperluan fungsional perangkat lunak. Pada pengujian Blackbox berfokus untuk menguji sistem dari sudut pandang fungsional sistem, apakah sistem berfungsi sesuai dengan fungsionalitasnya dan apakah hasil sudah sesuai dengan yang diharapkan, dan hasil pengujian sistem sudah sesuai dengan apa yang diharapkan.

DOI: $10.52362 /$ jisicom.v5i1.376

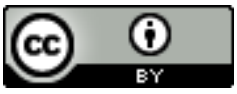

Ciptaan disebarluaskan di bawah Lisensi Creative Commons Atribusi 4.0 Internasional. 


\section{KESIMPULAN}

Berdasarkan dari hasil penelitian, analisis dan perancangan sistem, dan juga hasil dari implementasi yang telah diuraikan pada bab terdahulu, maka dapat diambil beberapa kesimpulan dari sistem yang telah dibangun sebagai berikut:

1. Telah dihasilkan suatu Sistem Informasi Geografis Berbasis Web Untuk Pemetaan Aset Kementerian PUPR pada Biro PBMN Jakarta secara online, yang dapat membantu Instansi terkait khususnya Biro Pengelolaan Barang Milik Negara Kementerian Pekerjaan Umum dan Perumahan Rakyat untuk dapat mengelola aset secara efektif dan efisien. Sistem informasi geografis berbasis web tersebut dapat menampilkan lokasi sebaran aset Biro Pengelolaan BMN Kementerian PUPR yang berada di Provinsi DKI Jakarta.

2. Terbentuknya sistem informasi geografis berbasis web ini bisa dimanfaatkan instansi terkait untuk mencari aset Biro Pengelolaan BMN Kementerian PUPR di Provinsi DKI Jakarta untuk memperoleh informasi dan lokasi aset, serta keterangan tambahan lain, juga dapat mencari rute terdekat dari posisi kita ke lokasi aset yang dituju

\section{REFERENASI}

[1] M. M. Dr. Siswo Hadi Sumantri, S.T, M. P. Makmur Supriyanto, B.Sc, S.Pd, S. Prof. Sobar Sutisna, M.Surv, and M. Dr. I Dewa Ketut widana, SKM, Sistem Informasi Geografis (Geographic Information System) Kerentanan Bencana, no. December. 2019.

[2] K. M. Wibowo, K. Indra, and J. Jumadi, "Sistem Informasi Geografis (SIG) Menentukan Lokasi Pertambangan Batu Bara di Provinsi Bengkulu Berbasis Website,” J. Media Infotama, vol. 11, no. 1, pp. 51-60, 2016, [Online]. Available: https://jurnal.unived.ac.id/index.php/jmi/article/view/252/231.

[3] E. B. Setiawan, "Sistem Informasi Geografis untuk Pemetaan Potensi Usaha Industri Kreatif,” vol. 2, no. 1, pp. 1-7, 2016.

[4] S. R. Puspitasari, M. Awaluddin, and H. S. Firdaus, "Pembuatan Aplikasi Webgis Untuk Informasi Persebaran Sarana Dan Fasilitas Kesehatan Dikabupaten Kudus,” J. Geod. Undip, vol. 7, no. 3, pp. 1-10, 2018.

[5] A. I. Yesiana, A. Suprayogi, and Hani'ah, "APLIKASI SISTEM INFORMASI GEOGRAFIS (SIG) PERSEBARAN HOTEL DI KOTA SEMARANG BERBASIS WEB,” Grivina Yuliantika, Andri Suprayoga, J. Gedesi Undip, vol. 5, no. April, pp. 200-207, 2016.

[6] D. Linda, "Merancang e-katalog Berbasis Website Sebagai Media Informasi pada Badan Perpustakaan Arsip dan Dokumentasi Daerah (BPAD) Lampung," Explor. J. Sist. Inf. dan Telemat., vol. 6, no. 2, 2016, doi: 10.36448/jsit.v6i2.637.

[7] M. Maudi, A. Nugraha, and B. Sasmito, "Desain Aplikasi Sistem Informasi Pelanggan Pdam Berbasis Webgis (Studi Kasus : Kota Demak),” J. Geod. Undip, vol. 3, no. 3, pp. 98-110, 2015.

[8] F. Rompis, Y. D. Y. Rindengan, and M. A. E. Sinsuw, "Rancang Bangun Sistem Penyediaan Dan Penerimaan File Digital Di LPPM Unsrat,” J. Tek. Elektro dan Komput., vol. 4, no. 5, pp. 51-56, 2015, doi: 10.35793/jtek.4.5.2015.9984.

[9] R. S. Utomo, A. L. Nugraha, A. Suprayogi, and Departemen, “APLIKASI PERSEBARAN LOKASI PENELITIAN MAHASISWA TEKNIK GEODESI UNDIP BERBASIS WEBGIS,” J. Geod. Undip, vol. 9, no. 1, pp. 275-284, 2019.

[10] A. A. Poipessy and M. Umasangadji, "Pembuatan Aplikasi Jadwal Kerja Karyawan Berbasis Web Pada Stasiun Pengisian Bahan Bakar Umum (Spbu) Kalumata Ternate,” IJIS - Indones. J. Inf. Syst., vol. 3, no. 1, pp. 37-45, 2018, doi: 10.36549/ijis.v3i1.40.

DOI: $10.52362 /$ jisicom.v5i1.376

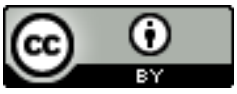

Ciptaan disebarluaskan di bawah Lisensi Creative Commons Atribusi 4.0 Internasional. 